REVISTA DE GESTÃO ESECRETARIADO

MANAGEMENT AND ADMINISTRATIVE

PROFESSIONAL REVIEW

ISSN: 2178-9010
Revista GeSec

São Paulo, SP, Brasil

v. 10 , n. 2 , p. $1-29$

mai/ago 2019

DOI: http://dx.doi.org/10.7769/gesec.v10i2.826

\author{
Danielle Santos da Silva Carvalho ${ }^{1}$ \\ Laís Karla da Silva Barreto ${ }^{2}$ \\ Lydia Maria Pinto Brito ${ }^{3}$ \\ Manoel Pereira da Rocha Neto ${ }^{4}$
}

\title{
Resumo
}

O objetivo geral deste estudo foi analisar o estágio atual da Gestão do Conhecimento (GC) na percepção dos secretários executivos de uma Instituição Federal de Ensino do Nordeste Brasileiro. Os objetivos específicos buscaram conhecer o perfil sócio demográfico dos secretários executivos; descrever o processo tático da Gestão do Conhecimento, utilizando-se de indicadores, nas etapas da obtenção, utilização, aprendizagem e contribuição do conhecimento na instituição; identificar o processo estratégico da Gestão do Conhecimento, utilizando-se de indicadores, nas etapas de avaliação, construção/manutenção e descarte do conhecimento. O modelo teórico utilizado foi o de Bukowitz e Williams (2002) com definição de variáveis em Brito, Oliveira e Castro (2012). É uma pesquisa descritiva de abordagem qualitativa que se configurou como um estudo de caso. Utilizando-se o modelo teórico foram investigadas as sete seções do conhecimento em seus níveis tático e estratégico. Os dados obtidos foram tratados em planilha eletrônica, onde os indicadores de Gestão do Conhecimento foram padronizados de acordo com Castro (2011). Os sujeitos da pesquisa foram os 15 secretários executivos da instituição estudada. Os resultados sinalizaram valores superiores aos propostos por Bukowitz e Williams (2002), retratando uma organização com resultado satisfatório para obtenção, construção, contribuição e utilização do conhecimento e um resultado de moderado para fraco quanto a aprendizagem, avaliação e descarte de informações. A organização precisa investir na capacitação de pessoas que exerçam a liderança em conhecimento, estimulando as equipes a explorarem seu potencial, refletindo sobre como seu trabalho pode trazer benefícios a instituição.

Palavras-chaves: Gestão do Conhecimento. Instituição Federal. Secretariado Executivo.

\footnotetext{
${ }^{1}$ Mestre em Administração, Secretária Executiva no Instituto Federal de Educação, Ciência e Tecnologia do Rio Grande do Norte (IFRN).

${ }^{2}$ Doutora em Estudos da Linguagem, Professora no Programa de Pós-Graduação em Administração da Universidade Potiguar (UNP).

${ }^{3}$ Doutora em Educação, Professora no Programa de Pós-Graduação em Administração da Universidade Potiguar (UNP).

${ }^{4}$ Doutor em Educação, Professor no Programa de Pós-Graduação em Administração da Universidade Potiguar (UNP).
} 


\begin{abstract}
The general objective of this study was to analyze the current stage of Knowledge Management (KM) in the perception of the Executive Secretaries of a federal educational institution of the Brazilian Northeast. The specific objectives sought to know the sociodemographic profile of the executive secretaries; to describe the tactical process of Knowledge Management, using indicators, in the stages of obtaining, using, learning and contributing knowledge in the institution; identify the strategic process of Knowledge Management, using indicators, in the stages of evaluation, construction/maintenance and disposal of knowledge. The theoretical model used was the Bukowitz and Williams (2002) definition of variables in Brito, Oliveira and Castro (2012). It was a descriptive research with a qualitative approach which is configured as a case study. Using the diagnostic model were investigated the seven sections of knowledge in their tactical and strategic levels. The data obtained were treated in a spreadsheet, where indicators of Knowledge Management were standardized according to Castro (2011). The research subjects were 15 executive secretaries of the institution studied. The results signaled values higher than those proposed by Bukowitz and Williams (2002), depicting an organization with a result considered satisfactory for obtaining, construction, contribution and use of knowledge and a result of moderate to weak in relation to learning, assessment and disposal of information. It was observed that the organization needs to invest in the training of persons exercising leadership in knowledge, stimulating the teams to exploit their potential, reflecting on how their work can bring benefits to the institution.
\end{abstract}

Keywords: Executive Secretariat. Federal Institution. Knowledge Management.

\title{
Introdução
}

Dada a compreensão de que a informação é fundamental para o crescimento organizacional, as instituições públicas de ensino, nos últimos anos, vêm demonstrando uma maior preocupação acerca da gestão do conhecimento. Isso porque, as diversas atividades que são realizadas no cotidiano dessas instituições, vem requerer delas um melhor gerenciamento de suas necessidades informacionais.

A Gestão do Conhecimento, segundo Sveiby (1998), é um processo organizado que inclui a identificação, criação, renovação e a aplicação de conhecimentos estratégicos e tem se consolidado como um fator determinante do sucesso, ajudando na criação da vantagem competitiva. A organização que sabe atuar na gestão de conhecimentos destaca-se por apresentar um diferencial estratégico que impulsionará seu desenvolvimento e a firmará no mercado. Em um ambiente escolar, onde a inovação e a geração de saberes se faz presente, o conhecimento ajuda a organização a ter mais possibilidade de se manter consolidada. 
Nessa perspectiva, o profissional de secretariado executivo, que tem seu trabalho focado no gerenciamento do fluxo de informações, passa a ser reconhecido como gestor do conhecimento, evidenciando suas habilidades informacionais, à medida em que ele passa a desenvolver trabalhos estratégicos com certo grau de complexidade atuando no planejamento institucional.

Por desempenhar o gerenciamento de informações no âmbito das organizações, exercendo papeis de intermediação, disseminação e administração informacional, percebe-se a necessidade de se desenvolver estudos que consolidem o secretário executivo como profissional da informação. Assim, nota-se um crescimento destes trabalhos, fazendo com que eles definam seu espaço nesse campo de estudo.

Devidos a mudanças no cenário informacional e organizacional, ocorre um acréscimo de trabalho e essas atividades ganham novo nível de complexidade. Talvez isso se configure devido a seu papel multifuncional que os permitem administrar o fluxo de informações com competência e profissionalismo.

No setor público, a atuação do secretário executivo está diretamente relacionada à informação. Com sua inserção recente aos quadros dos IFES, ocorrem responsabilidades acerca da gestão informacional. Esses profissionais, conforme contexto histórico, comumente eram vistos como profissionais que deveriam exercer um trabalho meramente tecnicista, no qual não se percebia atuação na parte estratégica, restringindo-se apenas às atividades burocráticas.

No entanto, as transformações sociais, econômicas e tecnológicas impõem às organizações uma maior produtividade e qualidade de seus serviços e/ou produtos. Consequentemente, a esfera pública vem exigindo de seus funcionários uma melhor qualificação para atendimento das crescentes demandas, além da preparação para novos desafios, uma vez que novos programas vão surgindo e, com isso, a gama de informações cresce e, com ela, vem o desafio de gerir cada vez mais conhecimento.

Nas instituições federais de ensino, atuantes nas atividades de ensino, pesquisa e extensão, há de se considerar que houve uma expansão considerável nos últimos anos. Esse 
contexto exige uma gestão integrada e focada nos processos de identificação das necessidades de informação e de conhecimento, bem como na sua aquisição, utilização, aprendizagem, compartilhamento, avaliação e construção/manutenção, buscando atender com eficiência as políticas institucionais. Segundo Pimenta (2010), é dentro desse contexto empresarial atual que a gestão do conhecimento acontece, objetivando oferecer um aporte para que as empresas conheçam, identifiquem e apliquem seu diferencial competitivo.

O secretário executivo, na qualidade de servidor público, atuante na sua área de formação deve assumir uma postura que lhe permita atuar em um contexto voltado para políticas organizacionais que atendam à missão institucional, desenvolvendo a capacidade de assimilar e aplicar o conhecimento de maneira efetiva. Para esse profissional, a gestão do conhecimento e a aprendizagem organizacional tornam-se essenciais para obter a excelência no desempenho das atividades administravas, contribuindo no desenvolvimento humano e institucional, uma vez que os servidores são detentores do conhecimento que agrega valor aos processos, produtos e serviços da instituição.

Diante desse contexto, o presente estudo se pautou na seguinte questão de pesquisa: Qual o atual estágio do processo de gestão do conhecimento na percepção dos secretários executivos de uma instituição federal de ensino? Nesse sentido, o objetivo geral do estudo foi analisar o estágio atual da Gestão do Conhecimento na percepção dos secretários executivos de uma Instituição Federal de Ensino do Nordeste Brasileiro. Para alcançar o objetivo geral, definiram-se os seguintes objetivos específicos: a) conhecer o perfil sócio demográfíco dos secretários executivos; b) descrever o processo tático da Gestão do Conhecimento, utilizandose de indicadores, nas etapas da obtenção, utilização, aprendizagem e contribuição do conhecimento na instituição; c) identificar o processo estratégico da Gestão do Conhecimento, utilizando-se de indicadores, nas etapas de avaliação, construção/manutenção e descarte do conhecimento. A presente pesquisa justificou-se devido a complexidade do tema, a carência e a deficiência de abordagem da Gestão do conhecimento aplicada ao universo secretarial. Assim o estudo estrutura-se com referencial teórico a respeito de gestão do conhecimento, o modelo que foi adotado para a pesquisa, metodologia, análise e discussão dos resultados. 


\section{Referencial teórico}

As organizações públicas estão cada vez mais se utilizando das ferramentas que sejam necessárias ao aperfeiçoamento da sua gestão estratégica. Isto inclui a Gestão do Conhecimento, cuja utilização ocorreu primeiramente nas empresas da iniciativa privada. Vêse que no processo a informação e o conhecimento andam de mãos dadas, entretanto, seus conceitos são distintos, embora colaborem para a mesma finalidade. Conhecer as distinções dos principais autores é imprescindível para o sucesso do trabalho. Embora tenham sido encontradas várias definições acerca de informação e conhecimento, elegeu-se as que mais contribuíram para o desenvolvimento da pesquisa. Sobre dados, Davenport \& Prusak (1998) elucidam que eles ajudam na descrição de um acontecimento, mas, apenas com eles, não tem como julgar nem interpretar informação, contudo, são insumos na criação da informação e, portanto, importantes para as organizações. Para eles, informação é mensagem e tem a finalidade de persuadir o destinatário.

Para Choo (2003), a informação é o produto do cotidiano do indivíduo. Segundo o autor, quem entende dessa forma (profissional ou a organização) tem a sua disposição um rico material que servirá para fomento da produção de conhecimento e da mesma maneira para o aprimoramento da tramitação de informações. Desta forma, os profissionais da organização necessitam reconhecer a relevância do conhecimento de cada indivíduo pois cada um pode contribuir para uma melhor gestão informacional, seja em menor ou em maior proporção.

O conhecimento é uma fusão de experiências, informações e insights para Davenport \& Prusak (1998). Para Figueiredo (2005), o conhecimento faz com que o indivíduo aja de forma adequada em determinadas circunstâncias. Nonaka \& Takeuchi (2008) complementam que o conhecimento é criado apenas pelos indivíduos. Rocha, Cardoso \& Torderas (2008) assumem que o conhecimento é um ajuste complexo de significados que se atribuem a experiências e acontecimentos multidimensionais, envolvendo necessariamente a interferência humana.

Eiriz, Gonçalves \& Simões (2007) referem-se ao conhecimento como algo distinto de opinião ou outros tipos de informações que não tenham sido provadas. Braun \& Mueller (2014) esclarecem que a diferença entre informação e conhecimento é o fator humano que, 
com sua interação, atua na potencialização e geração do conhecimento adicionando à informação sua prática. Para os autores, a geração do conhecimento depende da crença do indivíduo, sendo a junção de experiências que exercem influência em seu comportamento humano.

Estudiosos de várias áreas usam as palavras informação e conhecimento de formas diferentes e até com o mesmo sentido. Por isso, Wang \& Noe (2010) afirmam que os pesquisadores não chegaram a um consenso sobre as distinções, se houver, entre conhecimento e informação.

A informação correta transforma-se em conhecimento. Em um primeiro momento, o conhecimento tácito depende de assimilação de situações, informações e experiências para ser internalizado, e, em seguida, no decorrer do processo, posterior a assimilação de conteúdos, torna-se explícito quando acontece a comunicação; depois converte-se novamente em informação, estando em contínuo movimento. Corroborando com este entendimento estão Braun \& Mueller (2014) ao dizer que a ação resulta em conhecimento, de forma contínua, na interação da pessoa/informação. Os autores ainda esclarecem que a diferença entre informação e conhecimento é que o aspecto humano através de sua interpretação agrega valor à informação.

Os conhecimentos tácito e explícito, citados anteriormente, são os dois tipos consolidados e classificados por Nonaka \& Takeuchi (2008), sobre os quais discorremos em tópico específico. Garcia \& Coltre (2017) argumentam que os estudos que envolvem a gestão do conhecimento, geralmente, enfatizam o conhecimento explícito, o que consideram um ponto negativo, pois, para a realização da GC é necessário manter o foco tanto na dimensão tácita como na dimensão explícita.

Como os indivíduos estão sempre interagindo entre si, em ambientes internos e externos à organização, a informação recebida sofre influência não somente dos outros indivíduos, mas do próprio comunicador, em virtude de seus valores e crenças pessoais. Com essas interações sociais, a realidade organizacional vai sofrendo sua influência e acaba por agregar os relacionamentos e valores oriundos das realidades de cada indivíduo. Então, a cultura organizacional permanece em constante relação com a cultura externa, tendo em vista 
as inter-relações dos indivíduos com seus grupos internos e externos, e é dentro dela que a informação se concretiza.

\subsection{Gestão do Conhecimento}

Gestão do Conhecimento é um tema atual que desperta o interesse das organizações e, por consequência, chama atenção da academia. Embora seu ponto de partida não tenha sido nas empresas públicas e sim nas privadas, hoje se tem buscado aplicá-la nessas instituições, com vistas a gerenciar seu conhecimento. Conforme explica Azevedo (2002), mesmo tendo sido as organizações privadas a darem o pontapé inicial na adoção de estratégias para administrar o conhecimento organizacional, as entidades públicas, diante das ameaças e oportunidades, estão buscando novas formas de lidar com as pressões de uma sociedade exigente.

A partir da proposta de nova avaliação da economia mundial, deu-se início ao que chamamos de gestão do conhecimento. O termo iniciou a ser empregado na década de 1990 (Freitas, Chaga, \& Ribeiro, 2011). Leite (2007) chegou a afirmar que as organizações empresariais são o habitat natural da gestão do conhecimento. De acordo com a evolução histórica, resta claro que a Gestão do Conhecimento surgiu nas empresas de iniciativa privada e somente depois passou a ser adotada no setor público.

Com a competitividade aflorada no ambiente atual, a questão da gestão do conhecimento ganhou força nos últimos anos nas organizações, e vem sendo inclusa nas discussões que tratam do planejamento estratégico nas empresas. Sua aplicação engloba o interesse das empresas em identificar suas forças e fraquezas para, então, aplicarem seu potencial competitivo. Trata-se de um assunto complexo que agrega várias abordagens e definições. Vejamos que autores conceituados dissertam sobre a GC.

Gestão do conhecimento, para Sveiby (1998), é o processo que, de maneira sistematizada, identifica, cria, renova e aplica conhecimentos que podem ser estratégicos na vida de uma empresa. E estes processos ocorrem na administração dos ativos de conhecimento, permitindo à organização conhecer diversos aspectos fundamentais. Desta 
maneira, a empresa descobre os seus processos e procedimentos, buscando seu desenvolvimento por meio dos conhecimentos construídos em seu cerne.

Para Bukowitz \& Williams (2002), Gestão do Conhecimento trata-se do processo com o qual a organização utiliza seu conhecimento e consegue gerar riquezas. Para as autoras,

\begin{abstract}
A riqueza acontece quando uma organização utiliza o conhecimento para criar processos mais eficientes e efetivos. Como a reengenharia tradicional, isso tem impacto nos resultados financeiros por que diminui o custo (você não inventa a roda) ou porque reduz o tempo do ciclo (você obtém mais rápido o que necessita, entrega mais rápido para o cliente e o cliente lhe paga mais rápido) o que melhora o fluxo de caixa. A riqueza também acontece quando uma organização utiliza o conhecimento para criar valor para o cliente. Outro tipo de impacto ocorre quando os ativos intelectuais são utilizados para incentivar a inovação e promover o desenvolvimento de ofertas de mercado exclusivas que merecem um preço especial (Bukowitz \& Williams, 2002, p.18).
\end{abstract}

Por sua vez, Freitas, Chaga \& Ribeiro (2011), acreditam que a GC nas organizações se apresenta como uma maneira de administração, e quando aplicada na prática da empresa, pode agregar valor à informação, além de possibilitar a sua distribuição em benefício das empresas e dos atores que dela fazem parte. Colaborando com este pensamento, tem-se Brito, Oliveira \& Castro (2012), que afirmam que a GC se trata de um empenho em se utilizar e manter organizadamente as mudanças da empresa de forma a garantir uma melhor posição no mercado.

Em 1997, Nonaka e Takeuchi desenvolveram um modelo de criação do conhecimento em forma de espiral, desde então, tem surgido outros modelos com outros focos e componentes. Em 1998, foram apresentados três outros modelos de GC. Temos Sweiby, com o modelo de ativos intangíveis com foco nos negócios. Davenport e Prusak com o de geração de conhecimento. O de Stewart trazendo o Capital intelectual como fator de sucesso.

Nos anos de 2001 a 2005, houve a introdução de quatro outros modelos: Facilitação da criação do conhecimento (Von Krogh, Ichijo \& Nonaka), Diagnóstico de GC (Bukowitz e Williams), Criação de significado na organização do conhecimento (Choo) e Sete dimensões da GC (Terra).

Para Furlanetto \& Oliveira (2008), o reconhecimento de diferentes visões teóricas e características dos processos que buscam a identificação da gestão do conhecimento coopera 
para o entendimento de fatores desenvolvidos pelas empresas no processo de implantação de projetos específicos ao gerenciamento do conhecimento.

Com os avanços tecnológicos e comportamentais, acontecendo de forma acelerada, a GC no ambiente laboral deve acontecer de forma continuada e rápida, de forma que acompanhe essas transformações externas que ocorrem de forma acelerada na Era da Informação. As organizações que não agirem de forma rápida e eficaz, fatalmente ficarão para trás e provavelmente deixarão de existir. Soares et al. (2016), alegam que a gestão do conhecimento vem se destacando entre as organizações justamente pela necessidade de diferenciais competitivos, revertendo-se em vantagem organizacional.

Para Mülbert (2001), em virtude do avanço da tecnologia, das constantes mudanças e do crescimento da competitividade, uma área do conhecimento que vem sendo submetida a inúmeros desafios é a administração. Freitas Júnior (2003) aposta que, atualmente, empregar informações privilegiadas é administrar e que isso é aplicável a dirigentes universitários devido à necessidade de superintender os setores que atingem o funcionamento da instituição, em vários aspectos. Para este autor, a IES existe para prestar serviços à sociedade, sua matéria-prima é o conhecimento e como suas atividades (acadêmicas e administrativas) contribuem para o ensino, a pesquisa e a extensão, isso a torna uma organização singular.

\subsection{Modelo de Gestão do Conhecimento adotado na pesquisa}

O modelo adotado na pesquisa é o das autoras Bukowitz \& Williams (2002), um dos modelos mais aplicados nas pesquisas de Gestão do Conhecimento, que traz em sua composição um diagnóstico da gestão do conhecimento nas organizações, cuja distribuição se divide nos processos tático e estratégico. No modelo, há a divisão em sete seções. No tocante ao processo tático: obter, utilizar, aprender e contribuir. Em relação ao processo estratégico, tem-se: avaliar, construir/manter e descartar. Tal estudo sintetiza as ênfases presentes nos modelos anteriores e vem influenciando a criação de diversos modelos desenvolvidos após a sua publicação.

Da mesma forma que existem outros conceitos, também há outros modelos de Gestão do Conhecimento que apresentam variações de terminologias, entretanto, todos eles cooperam 
para o mesmo objetivo e finalidade que é identificar os pontos que necessitam de uma proposição.

É importante destacar que os outros modelos de Gestão do Conhecimento podem apresentar variações de terminologias, entretanto, possuem o mesmo objetivo e finalidade.

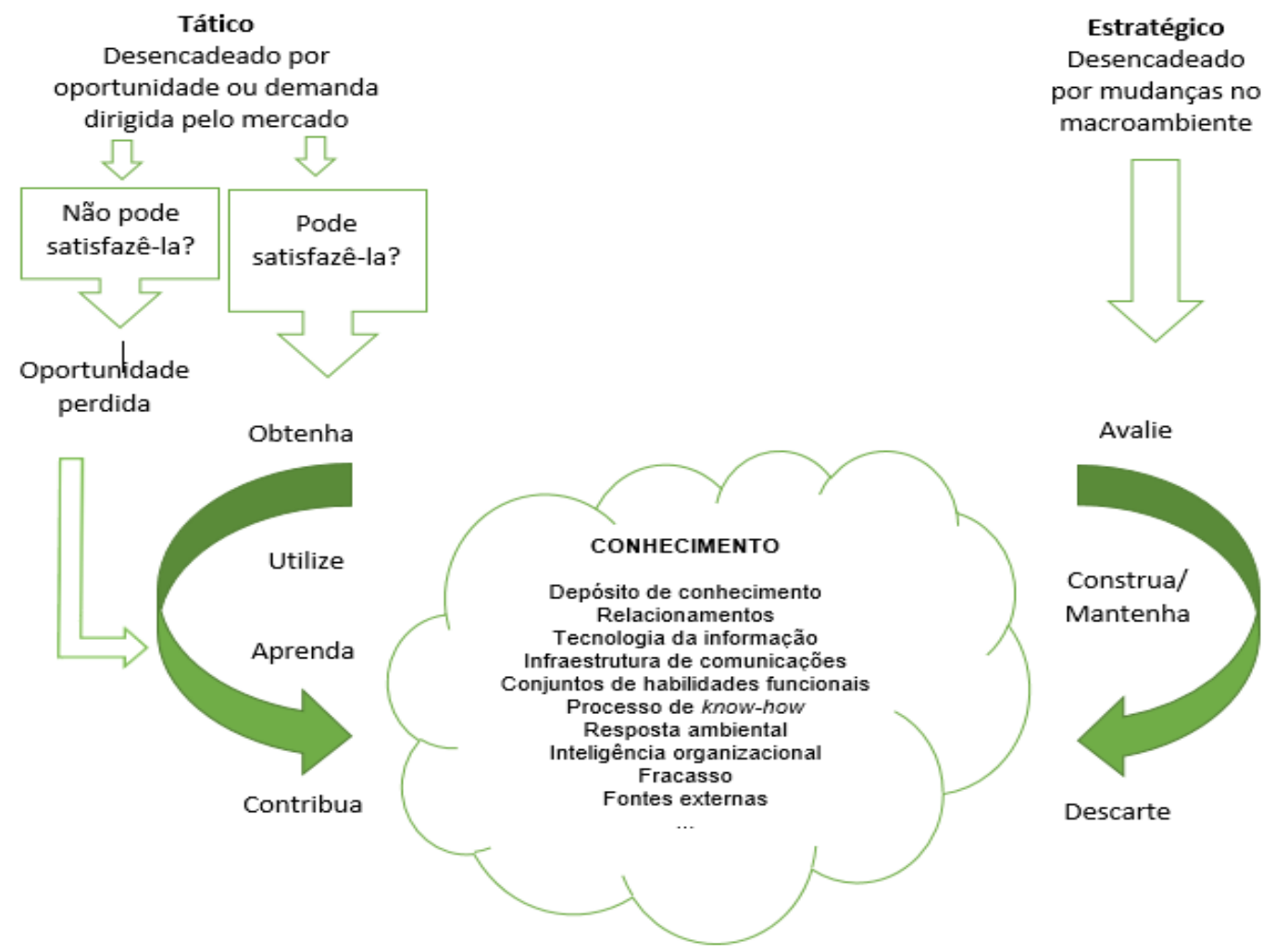

Figura 1. Estruturação do processo de Gestão do Conhecimento.

Fonte: Adaptado de Bukowitz \& Williams (2002, p.24).

Tendo em vista que o conhecimento é essencial para a organização permanecer no mercado elas devem, como desafio, realizar um processo de Gestão do Conhecimento que seja eficaz e eficiente e que contemple as etapas descritas: obter, utilizar, aprender, contribuir, avaliar, construir/manter e descartar, desenvolvendo técnicas para identificar os conhecimentos necessários. 


\section{Metodologia}

Esta pesquisa, quanto à sua natureza, é caracterizada como qualitativa. É um estudo de caso, quanto aos meios, pois envolve um estudo aprofundado de um limitado objeto, na visão de Yin (2001), permitindo esmiuçar-se sobre ele. É descritiva quanto aos fins, em consonância com Ventura (2007), que entende o estudo de caso como uma investigação específica. Aliado a esse entendimento, Prodanov \& Freitas (2013) esclarecem que o estudo de caso pode ter abordagem qualitativa e/ou quantitativa, por ser um tipo de investigação aprofundada de um objeto.

O público alvo deste estudo foram 15 secretários executivos dos campi da instituição estudada no Nordeste Brasileiro, visando o interesse em entender como profissionais de secretariado executivo podem trabalhar com Gestão do Conhecimento em uma IES. Os profissionais foram escolhidos devido possuírem diversas competências e ter se mostrado capazes de gerenciar o crescente fluxo de informações.

O principal instrumento de coleta dos dados foi o modelo proposto por Bukowitz \& Williams (2002). Tal instrumento, conhecido como Diagnóstico da Gestão do Conhecimento - DGC é composto por 140 questões, estando dividido em sete seções (Obtenha, Utilize, Aprenda, Contribua, Avalie, Construa/Mantenha e Descarte), cada uma das seções possui 20 questões objetivas. Também se realizaram entrevistas semiestruturadas com questões subjetivas.

A coleta de dados se tornou praticável tendo em vista a aprovação da pesquisa pela Diretoria de Gestão de Pessoas, na pessoa do diretor do setor, atendendo ao pedido da pesquisadora, através de e-mail. Os dados coletados foram obtidos via formulário eletrônico, que ficou disponível para respostas no período de outubro a dezembro de 2017, elaborado a partir da proposição de Bukowitz \& Williams (2002), por meio do google formulário que gerou um link enviado eletronicamente ao e-mail institucional dos respondentes. Para levantamento de outras informações no tocante a Gestão do Conhecimento os respondentes, lotados na reitoria da organização pesquisada, participaram de entrevistas, não gravadas, anotadas em papel, que consistia em 12 questões abertas. 
No tocante ao questionário, ressalta-se que, para cada pergunta, Bukowitz e Williams (2002) adotam uma escala de respostas gradativas com intensidade crescente de 1 a 3 pontos, variando entre fraco (Fr), moderado (Ms) e forte (Fs), conforme o Quadro 2.

Quadro 1

Escala de avaliação do questionário

\begin{tabular}{|c|c|}
\hline \multicolumn{2}{|c|}{ Pontuação das respostas } \\
\hline Respostas & Peso \\
\hline Fortemente descritiva (Fs) & 3 \\
\hline Moderadamente descritiva (Ms) & 2 \\
\hline Fracamente Descritiva (Fr) & 1 \\
\hline
\end{tabular}

Nota. Fonte: Bukowitz \& Williams (2002).

Consoante as autoras Bukowitz \& Williams (2002), a interpretação da pontuação dos resultados do DGC obedece ao seguinte critério: quanto maior o percentual obtido nas respostas, melhor o seu desempenho no processo de Gestão do Conhecimento. Para efetuar o cálculo de cada seção e suas respectivas médias é necessário utilizar a metodologia apresentada na próxima figura.

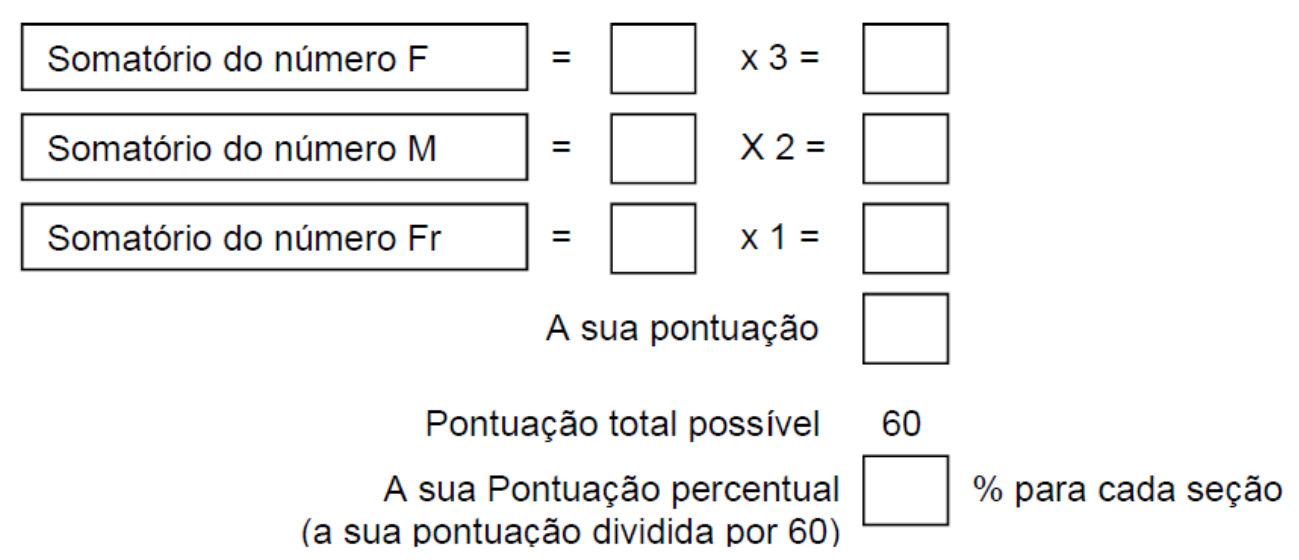

Figura 2. Método para cálculo por Seção.

Fonte: Bukowitz \& Williams (2020, p. 34).

A leitura pode ser adaptada de acordo com o número de participantes da pesquisa. A forma de se calcular por seção ocorre da seguinte maneira: são atribuídos pesos para as respostas do instrumento, scores ("Fs"=3, "Ms"=2 e "Fr"=1), o total de "Fs" é multiplicado por três; o de "Ms" por dois e o total de "Fr" é multiplicado por um. Somente é possível 
atingir uma pontuação máxima, em cada seção, de 60 pontos (20 afirmações x 3); assim, a pontuação máxima geral possível, incluindo todas as seções, é de 420 pontos, ou seja, 60 pontos x 7 seções. Na Figura 11, tem-se ainda o método para o cálculo geral por seção.
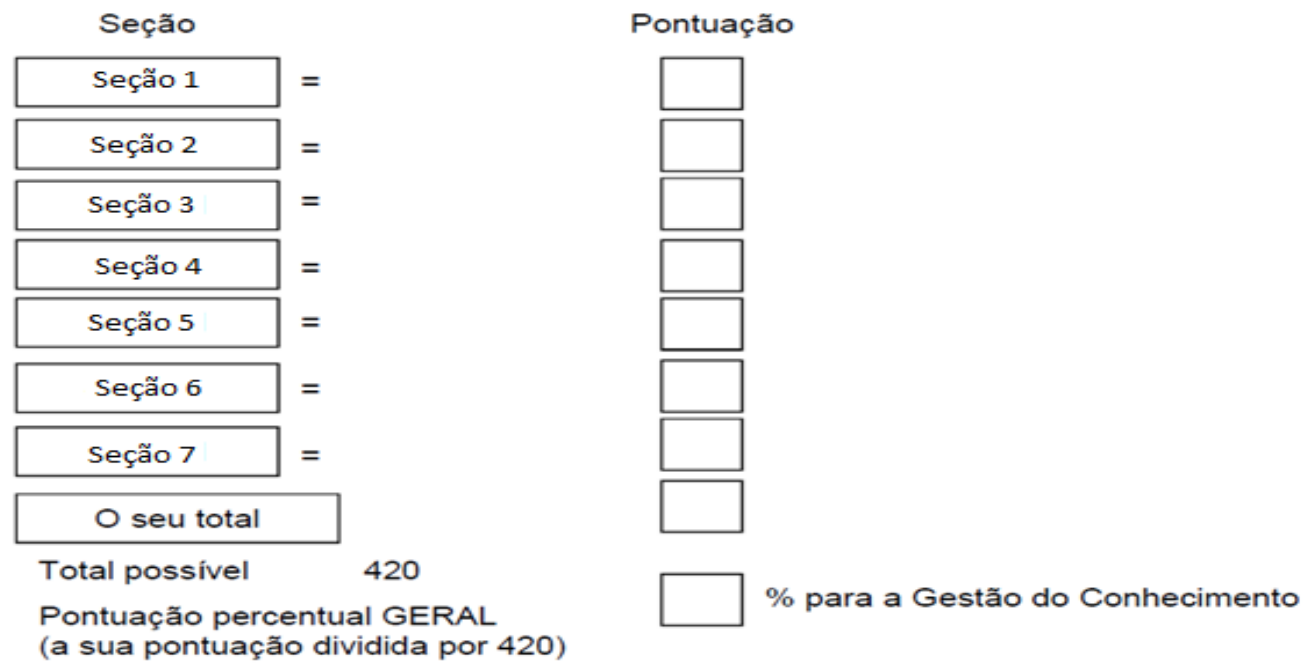

Figura 3. Método para cálculo Geral por seção Fonte: Bukowitz e Williams (2020, p. 47).

Como "padrão aceitável” de gestão do conhecimento, Bukowitz \& Williams (2002) estabelecem uma pontuação média, para cada seção de 30 a $70 \%$, e de $55 \%$ para todas as seções, tendo em vista que estas foram as médias encontradas em seus estudos.

\section{Análise e discussão dos resultados}

\subsection{Perfil dos pesquisados e da organização pesquisada}

A instituição estudada compõe a Rede Federal de Educação Profissional, Científica e Tecnológica, e possui mais de 100 anos de história. Contando com mais de 30 mil alunos matriculados em cursos técnicos, cursos de graduação, cursos de pós-graduação e cursos de qualificação profissional, está presente na capital e em diversos municípios do Estado do Rio Grande do Norte. Atualmente conta com vinte e um campi e um órgão administrativo central denominado Reitoria.

O grupo dos secretários executivos desta instituição apresenta uma preponderância do gênero feminino, dado que do total de 15 (quinze) respondentes, 11 (onze) são desse gênero, o 
que corresponde a um percentual de $73,33 \%$ e 4 (quatro) são do gênero masculino, ou seja, 26,67\%. A faixa de idade dos pesquisados apresenta uma superioridade dos secretários que têm idade compreendida entre 31 (trinta e um) a 40 (quarenta) anos. Com relação à escolaridade, em ambos os gêneros, a maioria dos pesquisados tem pós-graduações em nível de especialização ou MBA. Neste grupo a predominância é de profissionais especialistas, com tempo de exercício na instituição, compreendido entre 3 (três) a 4 (quatro) anos e que não ocupam cargo de gestão. Quanto ao tempo de experiência na profissão de secretariado executivo, a maior parcela indicou possuir mais de 6 anos, o que leva a crer que os profissionais da instituição têm experiências anteriores a ela.

\subsection{Diagnóstico da Gestão do Conhecimento}

Conforme preconizado por Bukowitz \& Williams (2002), o diagnóstico da gestão do conhecimento é factível através da análise das seções constantes no instrumento DGC para se descobrir o estágio atual da GC na instituição analisada. Para tanto, são apresentados abaixo os dados obtidos a partir da coleta e tratamento dos dados.

Tabela 1

Resultado geral das pontuações e percentuais obtidos por seção e por processo cognitivo

\begin{tabular}{|c|c|c|c|c|}
\hline \multicolumn{5}{|c|}{ Diagnóstico de Gestão do Conhecimento } \\
\hline Processo & Seção/Etapa & Pontuação & Porcentagem da pontuação & Desempenho \\
\hline \multirow{4}{*}{ Tático } & Obtenha & 653 & $72,56 \%$ & Melhor \\
\hline & Utilize & 618 & $68,67 \%$ & \\
\hline & Aprenda & 610 & $67,78 \%$ & Pior \\
\hline & Contribua & 634 & $70,44 \%$ & \\
\hline \multirow{4}{*}{ Estratégico } & Avalie & 530 & $58,89 \%$ & Pior \\
\hline & Construa/Mantenha & 654 & $72,67 \%$ & Melhor \\
\hline & Descarte & 611 & $67,89 \%$ & \\
\hline & Total Geral & 4310 & $68,41 \%$ & \\
\hline
\end{tabular}

Nota. Fonte: Dados da Pesquisa (2017). 
Os percentuais obtidos estão compatíveis com os limites recomendados na metodologia acolhida (30 a 70\% para cada seção) se localizando entre 58,89\% (seção Avalie) e 72,67\% (seção Construa/Mantenha). Registra-se o melhor e o pior desempenho geral no processo estratégico. É pertinente informar que, com relação aos melhores desempenhos, cada seção obteve resultados diferentes, isto é, nenhum indicador se repetiu. Já nos menores desempenhos, sucedeu o inverso, alguns indicadores se repetiram em algumas etapas. Dentre os indicadores que tiveram as menores pontuações, os que mais se repetiram foram: "processos decisórios" e "processos de gestão".

Aritmeticamente, o resultado geral aponta para um percentual acima da média estabelecida por Bukowitz \& Williams (55\%) para organizações praticantes da Gestão do Conhecimento, ficando em um total de $68,41 \%$. Parece claro afirmar que, na percepção dos secretários executivos, a organização pesquisada obteve um bom desempenho em relação a Gestão do Conhecimento.

A seção Obtenha se destacou por apresentar o melhor índice do processo tático, um percentual de 72,56\%, evidenciando a percepção positiva que seus funcionários têm de que a organização proporciona um ambiente propício a obtenção da informação, com ferramentas alinhadas às necessidades informacionais, facilitando o encontro de dados.

A seção Avalie assenta o pior desempenho geral (58,89\%), enquanto a seção Construa/Mantenha, componentes do mesmo processo estratégico, comporta o melhor resultado geral, 72,67\%. Resumidamente, os índices indicam que os secretários executivos da instituição têm dificuldade em avaliar estrategicamente o conhecimento obtido e, supostamente, estão dando ênfase em manter o conhecimento adquirido evitando seu descarte.

O Quadro 3 traz a descrição dos resultados dos objetivos específicos, de acordo com as repostas dos sujeitos na fase de coleta dos dados.

Quadro 2

\section{Resultado dos objetivos específicos}

\section{Perfil sócio demográfico}

Predominância do gênero feminino, com idade acima dos 31 anos. Com relação ao grau de escolaridade a maioria dos servidores possui especialização. Referente ao tempo de exercício na instituição a maior parcela possui de 3 (três) a 4 
(quatro) anos. Verifica-se ainda uma predominância dos servidores que não ocupam cargo de gestão. Se tratando do tempo de experiência na profissão de secretariado executivo, verificou-se que a maioria possui mais de 6 anos, o que retrata experiências anteriores. Sobre terem ouvido falar em Gestão do Conhecimento a maioria dos servidores pesquisados indicaram que sim.

\begin{tabular}{|c|c|c|c|}
\hline \multicolumn{4}{|r|}{ Processo Tático } \\
\hline Seção & Pontuação & $\begin{array}{l}\text { Porcentagem } \\
\text { da pontuação }\end{array}$ & Resultados dos objetivos específicos \\
\hline Obtenha & 653 & $72,56 \%$ & $\begin{array}{l}\text { Seção mais bem avaliada do processo tático. De forma moderada a forte, } \\
\text { os resultados autorizam concluir que, quando lhes são delegadas tarefas } \\
\text { que envolvam a pesquisa de informações, as pessoas conseguem realizá- } \\
\text { las, tendo um bom desempenho. Através dessa busca pelas informações } \\
\text { por parte das pessoas o conhecimento é obtido. Por outro lado, de forma } \\
\text { moderada, as pessoas não conseguem distinguir os papéis de gestão do } \\
\text { conhecimento, cujo foco está no conteúdo, bem como, elas têm } \\
\text { dificuldades em encontrar no momento necessário a informação correta. } \\
\text { Expressam a facilidade na obtenção de conhecimentos na instituição por } \\
\text { meio da capacidade de realização de tarefas de seus funcionários, } \\
\text { todavia, essa obtenção não tem sido usada para definir os papéis de } \\
\text { gestão organizacionais. }\end{array}$ \\
\hline Utilize & 618 & $68,67 \%$ & $\begin{array}{l}\text { Os resultados clarificam a utilização do conhecimento na estruturação de } \\
\text { parcerias que proporcionam o compartilhamento e a disseminação do } \\
\text { conhecimento. O indicador com o menor desempenho, foi o "Processo } \\
\text { decisório", significando que os servidores nem sempre têm a } \\
\text { compreensão do quanto suas decisões afetam o desempenho geral da } \\
\text { organização. Quer dizer que o recurso da parceria como forma de } \\
\text { utilizar os conhecimentos produzidos tem sido bem aproveitado, } \\
\text { contudo isso não se reflete na utilização dessas informações no processo } \\
\text { decisório, significando que ainda há pouco aproveitamento delas. }\end{array}$ \\
\hline Aprenda & 610 & $67,78 \%$ & $\begin{array}{l}\text { O melhor desempenho entre os indicadores foi o "Compartilhamento do } \\
\text { Conhecimento/Comunicação/Relacionamento", apontando que a } \\
\text { organização, com vistas a desenvolver seu capital intelectual, executa } \\
\text { ações orientadas para aprendizagem organizacional, o que facilita o } \\
\text { compartilhamento de informações e dificulta a perda de conhecimento. } \\
\text { Também indica que os funcionários percebem o compartilhamento de } \\
\text { informação útil ao seu trabalho específico. Entre os indicadores da seção } \\
\text { o menor desempenho foi do item "Processos de gestão do conhecimento } \\
\text { Contextualização/Política de Gestão do conhecimento", mostrando que } \\
\text { no ambiente organizacional o aprendizado, na perspectiva de reforçar os } \\
\text { processos de gestão do conhecimento, não tem ocorrido favoravelmente. }\end{array}$ \\
\hline Contribua & 634 & $70,44 \%$ & $\begin{array}{l}\text { O melhor desempenho entre os indicadores da seção Contribuir foi o } \\
\text { "Meios eletrônicos e tecnologias da informação", mostrando que a } \\
\text { organização tem construído uma boa estrutura, utilizando bem a } \\
\text { tecnologia da informação para o reforço das comunicações eletrônicas, } \\
\text { de forma que contribui para a gestão do conhecimento interno. Os locais } \\
\text { de armazenamento (físicos e eletrônicos) são mantidos atualizados, o } \\
\text { que auxilia os servidores a identificarem e darem melhor } \\
\text { encaminhamento da informação. Com o menor desempenho entre os }\end{array}$ \\
\hline
\end{tabular}




\begin{tabular}{|c|c|c|c|}
\hline & & & $\begin{array}{l}\text { indicadores da seção Contribuir, está "Processos de gestão do } \\
\text { conhecimento/Contextualização/Política de Gestão do conhecimento", } \\
\text { mostrando que, no momento, de moderado para fraco, existe pouca } \\
\text { consolidação de processos que contribuam de fato para o conhecimento } \\
\text { na organização, ou seja, não está havendo integração destes processos }\end{array}$ \\
\hline \multicolumn{4}{|r|}{ Processo Estratégico } \\
\hline Seção & Pontuação & $\begin{array}{l}\text { Porcentagem } \\
\text { da pontuação }\end{array}$ & Resultados dos objetivos específicos \\
\hline Avalie & 530 & $58,89 \%$ & $\begin{array}{l}\text { Seção com a menor pontuação dentre todas as etapas do DGC. O melhor } \\
\text { desempenho entre os indicadores foi o item "Processo decisório", } \\
\text { mostrando que a organização tem realizado processos avaliativos de } \\
\text { dados cujo objetivo é mensurar informações relevantes na tomada de } \\
\text { decisão, com isso, a tomada de decisões é feita com base em } \\
\text { documentos institucionais que mensuram e transformam fatos em dados } \\
\text { numéricos. Com o menor desempenho entre os indicadores da seção } \\
\text { Avalie, está "Documentação, resultados, mensuração/protocolos e } \\
\text { regras". Foi revelado que os serviços e produtos da instituição não são } \\
\text { entendidos como base do conhecimento. Por essa razão, a gestão do } \\
\text { conhecimento não é medida nem avaliada em nível organizacional, não } \\
\text { havendo, portanto, como mensurá-la. Como consequência, a } \\
\text { organização não realiza a avaliação mais crítica de seus produtos e } \\
\text { serviços numa dimensão baseada na informação e pode desconhecer } \\
\text { fatores relevantes a firmação de seu capital intelectual. }\end{array}$ \\
\hline $\begin{array}{l}\text { Construa/ } \\
\text { Mantenha }\end{array}$ & 654 & $72,67 \%$ & $\begin{array}{l}\text { Seção mais bem avaliada do processo estratégico. O melhor desempenho } \\
\text { entre os indicadores da seção está no item "Documentação, resultados, } \\
\text { mensuração/protocolos e regras", sugerindo que a organização é eficaz } \\
\text { no estabelecimento de regras e protocolos documentais. É revelado que } \\
\text { os servidores respondentes da pesquisa, no tocante a este item, acreditam } \\
\text { que seus produtos e serviços estão atrelados ao conhecimento, } \\
\text { percebendo sua dimensão intangível, ao mesmo tempo, conferindo um } \\
\text { valor mais alto ao que foi ofertado, visto que são frutos da construção e } \\
\text { manutenção de tal conhecimento. Com o menor desempenho entre os } \\
\text { indicadores está o item "Compartilhamento do } \\
\text { conhecimento/Comunicação/Relacionamento", mostrando que os } \\
\text { indivíduos não têm o hábito de se perguntar de que forma podem colocar } \\
\text { seu conhecimento a disposição de outras áreas. A instituição não só não } \\
\text { percebe quando não é adequado compartilhar externamente o } \\
\text { conhecimento, mas também, não coloca internamente a disposição de } \\
\text { todos os grupos o conhecimento para que qualquer pessoa na empresa } \\
\text { seja favorecida. }\end{array}$ \\
\hline Descarte & 611 & $67,89 \%$ & $\begin{array}{l}\text { O melhor desempenho entre os indicadores da seção Descarte, valida a } \\
\text { proposta de Bukowitz e Williams (2002). O item } \\
\text { "Simulação/jogos/inovação/resolução de problemas" mostra que a } \\
\text { organização coloca seus constructos para uso, testando e buscando } \\
\text { validá-los para que sejam utilizados como recursos informacionais, } \\
\text { oportunizando outras ideias de negócios relacionados a sua área. Indica } \\
\text { que os relacionamentos informais são feitos com o intuito de manter } \\
\text { atualizada sua base de conhecimentos. Com o menor desempenho entre }\end{array}$ \\
\hline
\end{tabular}




\begin{tabular}{|l|l|l|}
\hline \multirow{2}{*}{} & $\begin{array}{l}\text { os indicadores da seção Descarte, está "Processo decisório", mostrando } \\
\text { que as decisões de descarte do conhecimento, quando ocorrem, não } \\
\text { acontecem de forma consciente, ou seja, não são feitas de forma } \\
\text { estratégica, nem alicerçadas no capital intelectual e memorial da } \\
\text { organização. Resumindo, não há um planejamento estratégico da } \\
\text { maneira como esse processo deve se desenvolver e os servidores se } \\
\text { detêm mais em habilidades que não amparam suas competências } \\
\text { essenciais. }\end{array}$ \\
\hline
\end{tabular}

Nota. Fonte: Elaborado pelos autores (2017), com base nos dados coletados.

\subsection{Entrevistas}

Do universo de 15 secretários executivos pertencentes aos quadros funcionais da instituição, de forma amostral, foram entrevistados 8 desses profissionais que estão devidamente alocados na reitoria e representam mais de 50\% do total. As entrevistas consistiram em um total de 13 questões abertas, sendo a última delas de resposta livre, ou seja, tratava-se de um espaço destinado aos entrevistados para que pudessem fazer algum comentário ou contribuição para a pesquisa.

Nos casos de impossibilidade de algum respondente, optou-se por enviar as perguntas para o e-mail institucional dos mesmos, para que não deixassem de participar, contudo, a maioria foi entrevistada de forma presencial em seus setores de trabalho, corroborando com o entendimento de Flick (2013) que é o de que as entrevistas sejam tradicionalmente realizadas, na maior parte, presencialmente.

Quadro 3

Distribuição das respostas das entrevistas por questionamento

\begin{tabular}{|l|c|c|c|c|}
\hline \multicolumn{2}{|c|}{ Alternativa } & \multicolumn{3}{c|}{ Respostas } \\
\cline { 2 - 5 } & \multicolumn{2}{|c|}{ Afirmativas } & \multicolumn{2}{c|}{ Negativas } \\
\cline { 2 - 5 } & Frequência & $\%$ & Frequência & 0 \\
\hline $\begin{array}{l}\text { Contribuição do trabalho para o crescimento da } \\
\text { organização. }\end{array}$ & 8 & 100 & 0 \\
\hline $\begin{array}{l}\text { Chegada da informação (Contatos pessoais externos e } \\
\text { externos; telefonemas internos e externos; e-mail; internet; } \\
\text { documentos físicos). }\end{array}$ & 8 & 100 & 0 & 0 \\
\hline \begin{tabular}{l} 
Reconhecimento como gestor da informação \\
\hline
\end{tabular}
\end{tabular}




\begin{tabular}{|l|c|c|c|c|}
\hline Conhecimentos relevantes para organização/trabalho & 8 & 100 & 0 & 0 \\
\hline Ações de aprendizagem organizacional & 2 & 25 & 6 & 75 \\
\hline Entendimento sobre Gestão do Conhecimento & 8 & 100 & 0 & 0 \\
\hline $\begin{array}{l}\text { Identificação e apontamento de práticas de Gestão do } \\
\text { Conhecimento }\end{array}$ & 7 & 87,50 & 1 & 12,50 \\
\hline $\begin{array}{l}\text { Visualização das práticas no processo decisório } \\
\text { Formalização da Gestão do conhecimento }\end{array}$ & 8 & 62,50 & 3 & 37,50 \\
\hline $\begin{array}{l}\text { Apoio da alta gestão para inciativas de Gestão do } \\
\text { conhecimento }\end{array}$ & 7 & 87,50 & 1 & 12,50 \\
\hline $\begin{array}{l}\text { Avaliação para o descarte de informações } \\
\text { Contribuição dos processos eletrônicos na Gestão do } \\
\text { Conhecimento }\end{array}$ & 8 & 50 & 4 & 50 \\
\hline
\end{tabular}

Nota. Fonte: Elaborado pelos autores (2018), com base nos dados coletados.

No tocante ao item "Contribuição do trabalho para o crescimento da organização" foi perguntado aos entrevistados se acreditavam que seu trabalho poderia contribuir para o crescimento da organização e de que forma isso se dava. Como resposta, todos os entrevistados concordaram que seu trabalho contribui para o crescimento organizacional. Destaca-se a fala do respondente $n^{\circ} 2$ : "Hoje, acredito que sim. Meu chefe permite que eu atue dessa maneira, deixando que eu planeje e execute", levando a crer que nem sempre foi assim e que sua afirmativa se deve ao fato de que sua atual chefia imediata tem uma postura de confiança no trabalho do profissional.

Com relação ao item "Chegada da informação", algumas sugestões de resposta foram dadas, porém somente para uma melhor compreensão da pergunta, são elas: Contatos pessoais externos e externos; telefonemas internos e externos; e-mail; internet e documentos físicos. A maioria dos entrevistados indicou que embora a informação chegue de todas as formas sugeridas na alternativa sua maior demanda atualmente deriva dos meios ligados a tecnologia da informação. Destaca-se o relato do entrevistado n 7 : "A informação tem chegado em cima da hora, pelo menos, por parte da chefia, que solicita execução das tarefas imediatamente, o que acaba por definir tudo como sendo prioridade, mas, de fato, apenas foi resultado de planejamento insuficiente. Quando tudo é prioridade zero, acaba que nada passa a ser tão prioritário, já que as demandas surgem em cima da hora e qualquer atividade já vai ter o prazo 
bastante curto para realização". Isso explicita que em seu setor as demandas geralmente surgem de maneira inesperada, o que ele mesmo definiu como sendo "em cima da hora" e que, de igual modo, se espera uma resolução da demanda.

No item "Reconhecimento como gestor da informação", apesar de a maioria ter respondido afirmativamente ao questionamento, assegurando se reconhecer como profissional gestor da informação, houve alguns apontamentos, por parte dos que responderam negativamente, que atrelam suas respostas à questão da abertura que é facultada pela chefia imediata para que os profissionais que estão sob sua liderança desempenhem a gestão da informação. Também apontaram a importância da descentralização da informação o que remete à questão do compartilhamento indicador que teve o melhor desempenho na seção Aprenda, porém, o menor percentual na seção Construa/Mantenha. Tudo isso evidencia a ideia de que na organização analisada, os indivíduos não estão habituados a colocar seu conhecimento à disposição de outras áreas, consequentemente, esse não fica à disposição de todos.

Dois respondentes relataram pontualmente algumas questões. O respondente $n^{0} 1$ atrelou esse reconhecimento como gestor da informação à descentralização da chefia: "Não. Acho que depende da chefia. É importante a descentralização. Não adianta nadar contra a correnteza, tentei, mas não consegui mudar". Já o respondente $\mathrm{n}^{0} 7$ deixou clara a sua percepção de que não há espaço nem abertura para gestão da informação: "Não há espaço nem abertura para gerir informação. Apenas, cumpro ordens".

No tocante ao item "Conhecimentos relevantes", todos indicaram o que na sua ótica seria preciso conhecer para desenvolver suas atividades. As respostas para esta questão basicamente se resumiram ao acesso ao conhecimento, seja aquele ligado ao funcionamento da instituição ou aquele ligado ao conhecimento técnico profissional que os capacitam para o desempenho de suas atividades laborais. Os relatos indicam que os respondentes se sentem mais seguros para realização de suas tarefas cotidianas no ambiente de trabalho, refletindo o bom resultado do indicador "Capacidade de realização da tarefa" da seção Obtenha. O respondente $\mathrm{n}^{\mathrm{o}} 1$ teve dificuldades em identificar: "Para a organização fica difícil dizer porque cada pessoa concentra a informação que domina, com isso os outros não têm muito acesso". 
No item "Ações de aprendizagem organizacional", algumas sugestões de resposta foram dadas, para uma melhor compreensão da pergunta. São elas: capacitações, treinamentos entre outros. A maioria indicou um déficit nessas ações, considerando que a instituição realiza poucas ações voltadas para a aprendizagem organizacional, os que assim responderam levaram em conta as atividades voltadas especificamente para a área secretarial. De qualquer maneira, se entende que há a necessidade de se rever essas ações e atividades internas, de forma que as necessidades de capacitação de cada profissional procurem ser atendidas pela organização na medida do possível e respeitando-se as legislações em vigor. O respondente $\mathrm{n}^{\mathrm{o}}$ 2 foi taxativo: "Para o secretário executivo deixa a desejar, ou melhor, praticamente não existe. Aprendi no dia a dia, no sofrimento".

No tocante ao item "Entendimento sobre Gestão do Conhecimento" foi considerado pelos autores o ponto mais importante da entrevista, por estar diretamente relacionado ao problema de pesquisa obteve resposta afirmativa unânime. Cada profissional apresentou uma percepção diferente acerca do que vem a ser a gestão do conhecimento, dada a complexidade do tema, porém convergindo para o mesmo sentido. As diferentes compreensões complementaram umas às outras. Todos foram capazes de responder tal questionamento, significando que o assunto é conhecido, embora alguns tenham respondido durante a aplicação do questionário que não haviam ouvido falar em gestão do conhecimento. As respostas apresentadas se aproximaram da concepção de Terra (2005) por terem mencionado a aplicação de técnicas, o compartilhamento e administração de conhecimentos. De forma geral, os relatos apontam positivamente para a definição de Bukowitz e Williams (2002), ainda que nenhum tenha citado os termos riqueza e/ou capital intelectual, por entender que esses são aspectos que contribuem para o enriquecimento organizacional e que estão presentes nas etapas do Diagnóstico de Gestão do Conhecimento - DGC. Para o respondente $n^{0} 7$ : “Gestão do Conhecimento é uma forma de administrar todo o arcabouço de conhecimentos individuais e coletivos, aplicando instrumentos para disseminar uma cultura positiva e um ambiente de trabalho eficaz".

Com relação ao item "Identificação e apontamento de práticas de Gestão do Conhecimento", a maioria conseguiu visualizar e apontar as práticas. Isso confirma os resultados dos questionários quando a maioria dos respondentes indicou já ter ouvido falar em gestão do conhecimento. Ao serem capazes de definir o que significa a GC se tornou mais 
tranquilo o apontamento dessas práticas. Dois entrevistados não fizeram apontamentos. $\mathrm{O}$ respondente $\mathrm{n}^{\circ} 1$ foi claro: "Não consigo identificar" e o respondente $\mathrm{n}^{\mathrm{o}} 2$ declarou: "Sim, mas sem essa nomenclatura".

No tocante ao item "Visualização das práticas no processo decisório", a maior parte das respostas foi afirmativa significando que a visualização dessas práticas internamente é possível. A percepção da maioria é a de que as práticas se refletem no processo decisório da instituição. Essas justificativas são percebidas no resultado do indicador "processo decisório" da seção avalie que obteve o melhor desempenho reforçando a compreensão de que, com a realização de processos avaliativos que tem por intenção mensurar informações relevantes, a organização toma decisões com base nestes documentos institucionais. $O$ respondente $n^{0} 2$, sucintamente, afirmou: "Sim, elas refletem no processo decisório". O destaque foi para o respondente $\mathrm{n}^{\mathrm{o}} 7$ que aproveitou o espaço para pontuar: "Na verdade, servidores com menos capacitação possuem mais oportunidade de conquistar um cargo ou função do que outros que possuem mais tempo de serviço. O processo decisório não inclui cursos realizados ou atividades desempenhadas, mas sim a vontade política e a participação dos membros. "

No item "Formalização da Gestão do conhecimento", de forma unânime viu-se importância em se formalizar a gestão do conhecimento no âmbito organizacional. Partindose do Diagnóstico de Gestão do Conhecimento aplicado, o DGC, essas informações foram visíveis no baixo desempenho do indicador "Papéis de Gestão do Conhecimento" da seção Obtenha, confirmando que a organização pouco favorece atividades de equipes de especialistas em informação. Igualmente, no indicador "Processos de gestão do conhecimento/Contextualização/Política de Gestão do conhecimento" da seção Aprenda, reforça o pensamento de Nonaka e Takeuchi (2008) que vincula estas questões a possíveis conflitos e discordância de experiências. Na seção Contribua, o baixo desempenho neste mesmo indicador, substancia a ideia de que na organização há uma baixa consolidação dos processos que contribuam com o conhecimento.

Percebeu-se a complementação de duas respostas. A do respondente $\mathrm{n}^{\mathrm{o}} 1$ que sugeriu: "Seria interessante uma liderança em informação" e a do respondente $\mathrm{n}^{\mathrm{o}} 3$ propondo: "Acho que a gestão de pessoas deve pensar sobre isso. Acho que deve aproveitar as equipes que tem, não sei se deve criar novas equipes". 
No tocante ao item "Apoio da alta gestão para iniciativas de Gestão do conhecimento", a maior parcela, trazendo cada um para a realidade do seu setor de trabalho, respondeu de maneira afirmativa. Em três falas, foram citadas as chefias imediatas e em uma destas respostas, o respondente analisou a participação destas chefias no apoio à gestão do conhecimento. $\mathrm{O}$ respondente $\mathrm{n}^{\mathrm{o}} 1$ teve dificuldade em identificar esse apoio e declarou: "Não consigo visualizar".

Com as respostas dadas ao item "Avaliação para o descarte de informações" que objetivou entender o baixo desempenho das seções Avalie e Descarte do DGC, confirmou-se a dificuldade em avaliar e descartar informações, bem como, justificou-se o bom desempenho da seção Construa/Mantenha, indicando que, com a dificuldade de avaliar, os respondentes optam por manter a informação. Foram dadas algumas sugestões para orientar no entendimento da pergunta: exclusão de arquivos eletrônicos, descarte de documentos físicos, outros. Também se confirmou a dificuldade em se descartar informações dentro da organização. Esse resultado reforça as informações recolhidas por Moura (2016) em estudo anterior dentro da mesma instituição, conforme indica o respondente $\mathrm{n}^{\circ}$ 8: "Não há descarte de informações. Nada se perde, toda informação é armazenada para necessidades futuras".

No tocante ao item "Contribuição dos processos eletrônicos na Gestão do Conhecimento, com justificativas diferentes, todos responderam afirmativamente. Os relatos colocam como pontos positivos da implantação dos processos eletrônicos pontos como agilidade, criação de fluxos, otimização, democratização de atividades, padronização, acesso e disseminação da informação. Itens que estão presentes nas proposições de autores como Bukowitz e Williams (2002) e Terra (2005), reforçando os resultados positivos obtidos pela instituição no Diagnóstico de Gestão do Conhecimento - DGC. O respondente $n^{\circ} 6$ contribui dizendo: "Possibilita agilidade nos processos; padronização; criação de fluxos; discussão das rotinas administrativas (visto que para implantar um processo, é preciso saber o seu funcionamento) $"$.

Com a realização das entrevistas percebeu-se que os profissionais entrevistados estão abertos para falar e discutir a gestão do conhecimento na instituição. Verifica-se que eles têm buscado se aperfeiçoar e se capacitar ainda que a organização não disponha de um programa de capacitação pensado para este público. 


\section{Considerações finais}

A gestão do conhecimento, hoje, é algo relevante nas organizações públicas ou privadas. A compreensão da informação é fundamental para o crescimento organizacional e, com isso, as instituições públicas de ensino têm demonstrado uma maior preocupação acerca da gestão do seu conhecimento. Como um processo dinâmico, essa gestão envolve a participação dos indivíduos nos procedimentos de obtenção, utilização, aprendizagem, compartilhamento, construção, avaliação e descarte. Dada a complexidade das organizações, o planejamento estratégico deve ser pautado pela gestão do seu capital intelectual, porém, mesmo sendo indiscutivelmente necessário, a gestão do conhecimento se configura como um desafio para as instituições, contudo, os secretários executivos já percebem esse capital intangível.

O trabalho do profissional de secretariado se diferencia dos outros na medida em que esses profissionais atuam como gestores de informações, estando presentes, nos setores estratégicos da organização na qual está inserido, mantendo-se em contato com outras profissões. Muitas vezes, este é o profissional tido como referência para busca de informações por parte dos clientes, fornecedores e de sua equipe de trabalho. Com o avanço da tecnologia da informação, a profissão, que já percorreu um longo caminho, continuará passando por diversas transformações para se adaptar aos novos tempos. A cada dia, as organizações públicas terão a necessidade de ter em seu quadro funcional, servidores resilientes, conectados com o mundo, criativos, com capacidade de adaptabilidade, que sejam capazes de transformar dificuldades em ideias e materializá-las para transformar a realidade organizacional.

Nesta pesquisa procurou-se descobrir, através da realização de um diagnóstico de gestão do conhecimento, o estágio atual da gestão do conhecimento na percepção dos secretários executivos de uma Instituição de Ensino Federal.

Em relação ao primeiro objetivo específico, conhecer o perfil sociodemográfico do universo da amostra, após as análises dos dados, constatou-se a predominância do gênero feminino, com idade acima dos 31 anos. Com relação ao grau de escolaridade a maioria dos servidores possuem especialização, demonstrando que o grupo tem buscado o conhecimento além da graduação. Referente ao tempo de exercício na instituição, verificou-se que a maior 
parcela possui de 3 (três) a 4 (quatro) anos de exercício. Verifica-se ainda uma predominância dos servidores que não ocupam cargo de gestão. Em se tratando do tempo de experiência na profissão de secretariado executivo, verificou-se que a maioria possui mais de 6 anos, o que retrata experiências anteriores. Finalmente, sobre já terem ouvido falar em Gestão do Conhecimento a maioria dos servidores pesquisados indicaram que sim.

Por meio da análise dos resultados obtidos, conclui-se que, na percepção dos respondentes, a organização encontra-se em um nível aceitável do processo de Gestão do Conhecimento, conforme recomendado pelas autoras Bukowitz e Williams (2002), em todas as seções.

Com a pesquisa é possível perceber que na organização as pessoas detêm a capacidade de realizar tarefas delegadas; que utilizam o conhecimento produzido não somente em prol de seus objetivos; que estão dispostas a compartilhar conhecimento, cooperando para um ambiente de aprendizagem mútua; que a organização utiliza bem seus meios eletrônicos e de TI para o reforço da comunicação interna confiável; que processos avaliativos são realizados para a tomada de decisão; que a dimensão intangível do conhecimento é percebida, ainda que não seja nomeada; e que percebe a importância do descarte correto das informações.

Dentro da proposição das autoras Bukowitz \& Williams (2002), analisando os objetivos específicos, verifica-se que a organização galgou níveis aceitáveis de gestão do conhecimento no processo tático (Obtenha, Utilize, Aprenda e Contribua) e no processo estratégico (Avalie, Construa/Mantenha e Descarte). A seção que conseguiu a melhor pontuação no processo tático foi a Obtenha $(72,56 \%)$, enquanto que a menor pontuação do processo estratégico se revelou na seção Avalie (58,89\%).

Em relação ao segundo objetivo específico, cuja proposição era conhecer a forma de obtenção da informação na instituição, a seção Obtenha (72,56\%), com a melhor pontuação, demonstra que a organização propicia um ambiente favorável à obtenção da informação, utilizando as ferramentas disponíveis, inclusive as de TI como recurso a informação. Com a capacidade de execução de tarefas de seus servidores a organização tem se beneficiado, posto que as pessoas estão dispostas a obter e compartilhar conhecimento. Por outro lado, no tocante ao sexto objetivo específico proposto, a seção Avalie $(58,89 \%)$, com a menor 
pontuação do DGC, permanece como um dos maiores problemas da instituição estudada, significando que ainda há dificuldade em se avaliar a informação que é relevante para ela, impedindo que seja utilizada como estratégia para geração de valor. Em vista disso, a proposição é a de que a organização estabeleça a avaliação do conhecimento de forma contínua e rotineira, compreendendo os fluxos do conhecimento para entender as necessidades de gestão e seus resultados.

Com isso, conclui-se que a organização pesquisada teve um resultado considerado satisfatório quanto à obtenção, construção, contribuição e utilização do conhecimento e um resultado de moderado para fraco no que se refere a aprendizagem, avaliação e descarte de informações. A baixa compreensão acerca da $\mathrm{GC}$, o não compartilhamento de experiências por parte de alguns grupos somada a deficiência de capacitação de pessoal são alguns impeditivos à implementação da GC no ambiente organizacional. Dessa forma, observa-se que a organização precisa investir na capacitação de pessoas que exerçam a liderança em conhecimento, estimulando as equipes a explorarem seu potencial, refletindo sobre como seu trabalho pode trazer benefícios à própria instituição. Sugere-se que o instituto, estrategicamente, impulsione a interação entre as equipes de trabalho para que o conhecimento fique disponível a todos. Outra sugestão é a de que os servidores procurem conhecer melhor a gestão do conhecimento para tornar suas ações de gestão mais conscientes e coerentes com ela, consolidando processos que contribuam para a análise e descarte de informações não mais necessárias.

As entrevistas realizadas serviram para enriquecer a pesquisa e agregar informações que possam ser utilizadas para a melhoria da gestão da informação organizacional. Com as respostas coletadas se tornou possível confirmar e compreender os indicadores que obtiveram menor pontuação no questionário DGC e também mostrou que ainda que alguns profissionais que na época da aplicação do questionário responderam que nunca tinham ouvido falar em gestão do conhecimento ou ainda que quem respondeu ter escutado a respeito, tenha ouvido fora da instituição, foram capazes de apresentar sua percepção sobre o tema e apontar as práticas que acreditam serem realizadas internamente.

Uma vez que o estudo da gestão do conhecimento é muito complexo e requer um aprofundamento de cada etapa do modelo, é preciso reconhecer as limitações da pesquisa: 
a maioria dos artigos de secretariado estão publicados em anais de eventos, geralmente, congressos e seminários, por isso, nem sempre tem pontuação no CAPES; são poucas as revistas científicas especificamente direcionadas ao secretariado executivo brasileiro; poucas dissertações e teses na área secretarial, mesmo com o surgimento de trabalhos científicos que reconhecem o SE como profissional da informação, ainda é mais fácil constatar que a maior parte dos trabalhos acadêmicos focam nas competências técnicas da profissão.

Quanto às contribuições práticas do presente trabalho, espera-se que os resultados desta pesquisa possam colaborar para que a instituição, reveja aspectos da gestão do conhecimento de forma a melhorar os pontos positivos e corrigir eventuais equívocos que culminaram em uma avaliação negativa de alguns pontos gerenciais.

Com relação às contribuições teóricas, espera-se efetivar uma contribuição científica empírica significativa relacionada aos estudos sobre gestão do conhecimento e secretariado executivo, contribuindo assim, com o aperfeiçoamento dos assuntos em estudos futuros.

Vislumbra-se trabalhos futuros que contribuam para a literatura das pesquisas relacionadas à gestão do conhecimento e secretariado executivo, para tanto, sugere-se: realizar o diagnóstico entre outros grupos profissionais da instituição; replicar a pesquisa nos grupos de secretários executivos da universidade federal buscando realizar um estudo comparativo com os resultados desta pesquisa para investigar a percepção da gestão do conhecimento entre Instituições Federais de Ensino; estender essa pesquisa a grupo de secretários executivos de outras organizações públicas ou privadas, do nordeste brasileiro; examinar a relação entre a atuação do SE e a gestão informacional; englobar clientes e fornecedores da organização nas próximas pesquisas.

\section{Referências}

Azevedo, L. C. S. (2002). Gestão do Conhecimento em organizações públicas. Rio de Janeiro: Rio Estudos $n^{\circ} 67$.

Braun, Carla Cristine, \& Mueller, Rafael Rodrigo. (2014). A gestão do conhecimento na administração pública municipal em Curitiba com a aplicação do método OKA Organizational Knowledge Assessment. Revista de Administração Pública, 48(4), 9831006. https://dx.doi.org/10.1590/0034-76121620 
Brito, L. M., Oliveira, P. W., \& Castro, A. B. (2012). Gestão do conhecimento numa instituição pública de assistência técnica e extensão rural do Nordeste do Brasil. Revista de Administração Pública.

Bukowitz, W. R., \& Williams, R. (2002). Manual de gestão do conhecimento: ferramentas e técnicas que criam valor para a empresa. Porto Alegre: Bookman.

Choo, C. W. (2003). A Organização do conhecimento: como as organizações usam a informação para criar significado, construir conhecimento e tomar decisões. São Paulo: Senac.

Cavalcanti, G. M. (2016). Gestão do Conhecimento em Instituição de Ensino: percepção de gestores (Dissertação de Mestrado Profissional em Administração, Universidade Potiguar, 2016).

Davenport, T., \& Prusak, Laurence. (1998). Conhecimento empresarial: como as organizações gerenciam o seu capital intelectual. Rio de Janeiro: Campus.

Eiriz, V., Gonçalves, M., \& Simões, J. (2007). Obstáculos à gestão do conhecimento nas escolas de gestão e economia do ensino superior público em Portugal. Comportamento Organizacional e Gestão, 153-167.

Flick, U. (2013). Introdução à pesquisa qualitativa: um guia para iniciantes. Porto Alegre: Penso.

Freitas Júnior, O. G. (2003). Um modelo de sistema de gestão do conhecimento para grupos de pesquisa e desenvolvimento (Tese de Doutorado em Engenharia de Produção, Universidade Federal de Santa Catarina, 2003).

Freitas, R. P., Chaga, M. M., \& Ribeiro, N. (2011). A Gestão do Conhecimento e da Carreira Profissional. Natal: Edunp.

Figueiredo, S. P. (2005). Gestão do conhecimento: estratégias competitivas para a criação e mobilização do conhecimento na empresa. Rio de Janeiro: Qualitymark.

Furlanetto, A., \& Oliveira, M. (2008). Fatores estratégicos associados às práticas de gestão do conhecimento. Revista Análise, 99-123.

Garcia, O., \& Coltre, S. (2017). Knowledge Management as a Determining Factor in the Retention of Professionals in the Industry: A Case Study in an Organization in the Furniture Industry. Brazilian Business Review, 182-203.

Leite, F. C. (2007). Comunicação científica e gestão do conhecimento: enlaces conceituais para a fundamentação da gestão do conhecimento científico no contexto de universidades. Transinformação, 139-151.

Mülbert, A. L. (2001). Proposta de um sistema de informações para a gestão acadêmica de cursos de graduação: o caso da UNISUL (Dissertação de Mestrado, Universidade Federal de Santa Catarina, 2001).

Nonaka, I., \& Takeuchi, H. (2008). Gestão do Conhecimento. Porto Alegre: Bookman. 
Prodanov, C. C.; \& Freitas, E. C. (2013). Metodologia do trabalho científico: Métodos e Técnicas da Pesquisa e do Trabalho Acadêmico. Novo Hamburgo: Universidade Feevale.

Pimenta, R. C. Q. (2010). Gestão do conhecimento e inteligência competitiva. Natal: Edunp.

Rocha, F. S.; Cardoso, L. \& Tordera, N. (2008). The importance of Organizational Commitment to Knowledge Management. Comport. Organ. Gest., Lisboa, vol. 14, n. 2, pp. 211-232, 2008.

Soares, A. M. (2016). Gestão do conhecimento sob a percepção de gestores: estudo de caso em empresas madeireiras. Revista Espacios, 4-15.

Sveiby, K.-E. (1998). A nova riqueza das organizações, gerenciando e avaliando patrimônios de conhecimento. Rio de Janeiro: Campus.

Terra, J. C. C. (2005). Gestão do Conhecimento: o grande desafio empresarial. Rio de Janeiro: Elsevier.

Yin, R. K. (2005). Estudo de Caso: Planejamento e métodos. Porto Alegre: Bookman.

Wang, S., \& Noe, R. (2010). Knowledge sharing: A review and directions for future research. Human Resource Management Review, 115-131. doi:http://dx.doi.org/10.1016/j.hrmr.2009.10.001

Submetido em: 23.05.2018

Aceito em: $\quad 11.04 .2019$ 